\title{
AS THE BASIS OF THE AXIOLOGICAL-PEDAGOGICAL CONCEPT OF MORALITY EDUCATION
}

(C) 2019

\author{
Guschina Anna Vladimirovna, candidate of pedagogical sciences, associate professor, \\ vice rector for academic and educational work \\ Murmansk Arctic State University (Murmansk, Russian Federation)
}

\begin{abstract}
The task of this paper is to determine the value underlying the idea «Create the world of conscience and good», which is the backbone inner core of teaching morality to prospective teachers. Evidence is given that the value underlying the idea «Create the world of conscience and good» is the value of the golden rule of morality. The author shows the significance of the golden rule of morality in teaching morality to prospective teachers. The author also formulates a generalized goal of teaching morality to prospective teachers: a person who is able to live in morality. It is proved that the idea is a system-forming internal core of axiological and pedagogical activity as an activity of teaching morality to prospective teachers. The paper explains the use order of the terms «axiological» and «pedagogical» in the concept of «axiological-pedagogical activity» on the basis of methodology levels. The author reveals the content of axiological and educational activities and specifies features of the value relationship as one of the formative content of such activities. The author shows that the use of the golden rule of morality as a criterion for assessing realized, professed, and disseminated values makes it possible to show whether such values are really values, or anti-values.

Keywords: upbringing; prospective teacher; value; idea; system-forming inner core of axiological-pedagogical activity; golden rule of morality; personal necessity; two-way movement of value of morality golden rule; purpose of teaching morality to prospective teacher; particular values.
\end{abstract}

\section{САМОРАЗВИТИЕ СТУДЕНТОВ СКВОЗЬ ПРИЗМУ ЭЛЕКТРОННОГО ПОРТФОЛИО}

Добудько Татьяна Валерьяновна, доктор педагогических наук, профессор, заведующий кафедрой информатики, прикладной математики и методики их преподавания

Горбатов Сергей Васильевич, кандидат педагогических наук, доцент кафедры информатики, прикладной математики и методики их преподавания Добудько Александр Валерьянович, кандидат педагогических наук, доцент кафедры информатики, прикладной математики и методики их преподавания

Пугач Ольга Исааковна, кандидат педагогических наук, доцент кафедры информатики, прикладной математики и методики их преподавания Самарский государственный социально-педагогический университет (2. Самара, Российская Федерация)

Аннотащия. В данной статье рассматривается одна из актуальных задач высшего образования на современном этапе - формирование личности специалиста, способного к саморазвитию в условиях цифровизации образования Российской Федерации. Формирование системы непрерывного образования в России в первую очередь является результатом этого процесса, так как самообразование специалиста - это необходимое условие успешного трудоустройства, карьерного роста, социальной и профессиональной мобильности в настоящее время. При этом потребности и возможности различных форм непрерывного образования неравномерно распределены в различных отраслях. Так, для ІТ-отрасли требуется постоянное самообразование сотрудников. Практика показывает, что среднее общее образование, как правило, не формирует у выпускников необходимых навыков самообразования. Поэтому вопросы управления саморазвитием бакалавров, формирования готовности к непрерывному образованию являются весьма актуальными для высшей школы. В статье описаны условия формирования готовности бакалавров к продолжению образования в различных его формах (формальное, неформальное, информальное) с использованием системы электронного портфолио, являющейся неотъемлемой частью электронной информационно-образовательной среды (ЭИОС) вуза. Полученные материалы могут служить основой для разработки единого электронного образовательного пространства вузов России.

Ключевые слова: цифровизация образования; электронная информационно-образовательная среда; электронное образовательное пространство; непрерывное образование; самообразование; саморазвитие; электронное портфолио; культура самостоятельной работы личности; академическая мобильность; работодатель; высшее образование.

\section{Постановка проблемы в общем виде и ее связь с важными научными и практическими задачами}

Проблема качественной подготовки востребованного на рынке труда специалиста в системе высшего профессионального образования не нова, однако в современных условиях она приобретает особую ост- роту. Как видно из рисунка 1 , существенный процент выпускников 2014-2016 года (от 3\% медиков до 30\% в сфере энергетического машиностроения) трудоустроились не в соответствии с полученной специальностью.

Причин указанному явлению множество - от принципиальной невозможности с абсолютной точ- 
ностью прогнозировать потребности рынка труда, постоянно изменяющихся требований к специалистам во многих активно развивающихся областях (информационные технологии, экономика, менеджмент) [2, с. 75] до низкого качества подготовки в системе высшего образования или, напротив, низкого уровня зарплат в ряде сфер, к примеру, в дошкольном образовании. Одним из традиционных путей решения указанной проблемы выступают либо переподготовка [3], либо, в качестве более глобального подхода, система непрерывного образования [4].

\section{Анализ последних исследований и публикаций, в которых рассмат- ривались аспекты этой проблемы и на которых обосновывается автор; выделение не разрешенных ранее частей общей проблемы}

Однако, невзирая на огромное число теоретических исследований, публикаций, посвященных раз- личным аспектам непрерывного образования [5-12], можно констатировать (рис. 2), что население России в возрасте 15-23 лет (выпускники школ, организаций среднего профессионального образования, бакалавриата) не готовы к продолжению обучения.

По данным показателям наблюдается существенное отставание России от стран Европы: так, в Швейцарии в непрерывном образовании в 2016 участвовало $60 \%$ населения, в Германии - 52\%, а в России - только $17 \%$. Чуть меньше разрыв показателей по самообразованию - 26\% в России против 44\% в Германии.

\section{Формирование цели статьи \\ (постановка задания)}

Цель нашего исследования - рассмотреть условия формирования готовности бакалавров к продолжению образования в различных его формах (формальное, неформальное, самообразования) с использованием системы электронного портфолио вуза.
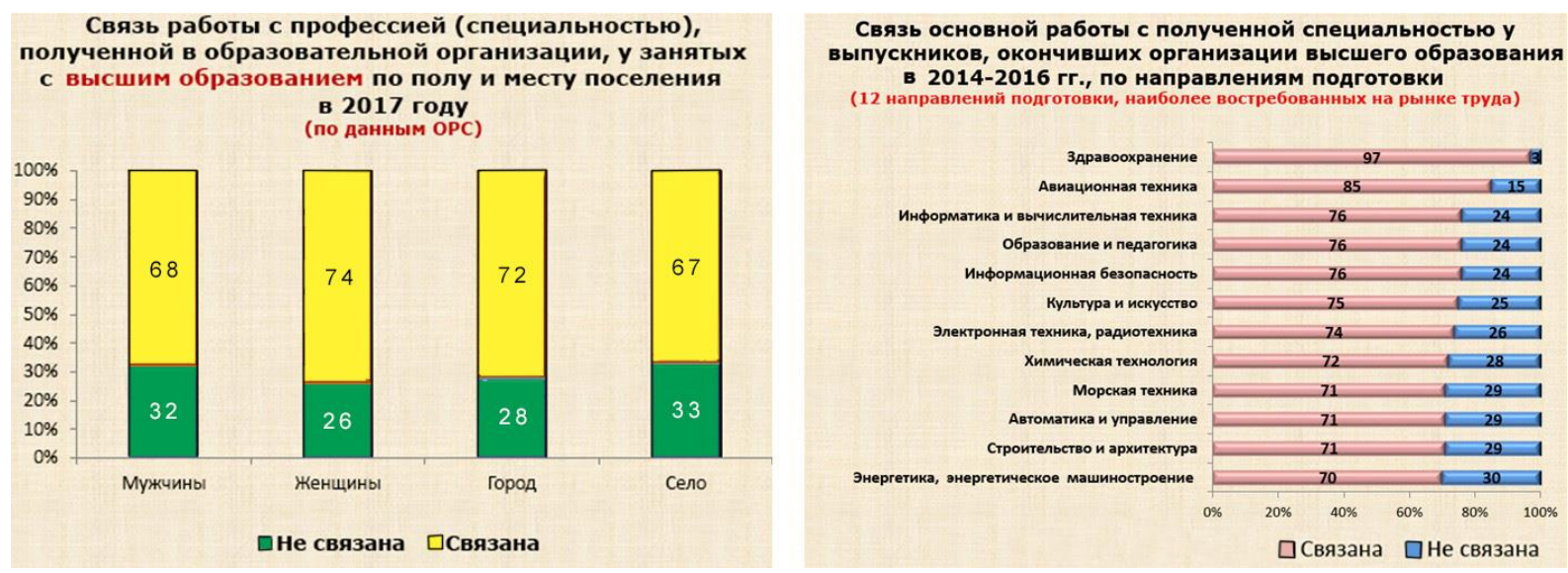

Рисунок 1 - Эффективность высшего образования для карьеры выпускника (по данным [1])

\section{6. НАМЕРЕН ИЕ ПРОДОЛЖИТЬ ОБУЧЕН ИЕ НАСЕЛЕНИЯ В В 03 РАСТЕ 15-23 ЛЕТ ПО В 03 РАСТНЫМ ГРУППАМ: 2016 *} (в процентах от обияей численности респондентов в возрасте 15-23 лет по соответствующей группе)

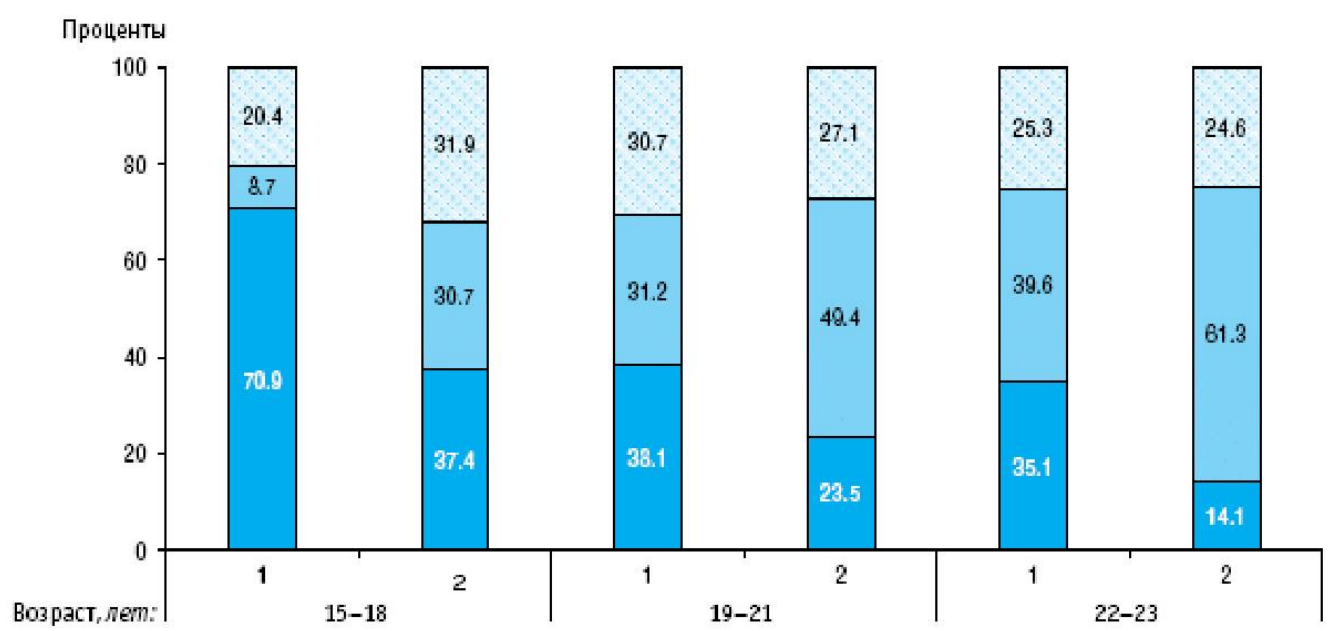

1 - обучаются в образовательной организации *
2 - не обучаются в образовательной организации
Собираются продолжить обучение Не собираются продолжить обучение Не определились

* По данным Комплексного наблюдения условий жизни населения.

* З За исключением респондентов, обучающихся по програкмам подготовки кадров высшей квалификации.

Рисунок 2 - Намерение продолжить обучение (по данным [13, с. 39]) 


\section{Изложение основного материала исследования с полным обоснованием полученных научных результатов}

Предваряя дальнейшее обсуждение проблемы, определимся с используемой терминологией. «Неформальное образование включает организованные виды обучения, которые не являются частью программ формального образования, - курсы повышения квалификации, профессиональные и любительские курсы; лекции, семинары, тренинги... В международной практике используется показатель участия населения в неформальном образовании, который учитывает долю лиц, получавших неформальное образование в течение последних 12 месяцев, среди населения в возрасте 25-64 лет» [13, с. 52]. «Самообразование (информальное образование) - индивидуальное обучение, которое в отличие от формального образования и неформального образования не фиксируется получением диплома или иного документа, но вносит вклад в расширение знаний и умений. В международной практике используется показатель участия населения в самообразовании, который учитывает долю лиц среди населения в возрасте 2564 лет, получавших в течение последних 12 месяцев знания и навыки самостоятельно с помощью печатных материалов (профессиональных книг, журналов и т.п.); технических средств (аудио- и видеозаписей, компьютеров, интернета); при посещении заведений, ориентированных на передачу знаний (библиотек, музеев, выставок, театров, кино и т.п.); при прослушивании учебных передач по радио, просмотре по телевидению; под руководством родственников, друзей, коллег по работе и др.» [13, с. 52].

Приведенная на рисунке 3 динамика наглядно показывает, что, невзирая на отдельные колебания (обусловленные в первую очередь состоянием экономики в 2008-2009, 2014-2015 годах, а также изменением методологии расчета показателей в 2015 году) наблюдается тенденция роста доли населения, вовлеченного в неформальное и информальное образование. Таким образом, можно констатировать необходимость формирования готовности студентов к этим формам обучения.

Ключевая проблема формирования указанной готовности - формирование культуры самостоятельной работы личности в системе непрерывного образования [14]. И здесь, среди традиционных подходов к организации самостоятельной работы студентов, просматривается два перспективных направления. Первое предусматривает включение разнообразных учебных материалов сети Интернет в учебный процесс и, тем самым, углубленное знакомство обучающихся с возможностями для формального, нефор- оразвитие студентов сквозь призму электронного портфолио

мального и информального обучения [2;15-18]. Заметим, что в некоторых вузах это сопровождается и материальным стимулированием студентов - сертификаты онлайн-курсов учитываются при назначении особых видов стипендий (научная). При всех достоинствах данного подхода необходимо избегать крайностей: подмена грамотных научно-методических материалов, прошедших экспертизу, роликами на ютубе за авторством таких же студентов [2, с. 77], может, и сделает решение отдельных задач более доступным, но вряд ли будет способствовать формированию тезауруса, развитию мышления, естественнонаучного мировоззрения будущих бакалавров. Особенно опасен «кнопочный» метод, когда автор разработки в сфере информатики подменяет решение практической задачи указанием точной последовательности действий в виде формальной видео- или текстовой инструкции.

Второй подход подробно изложен в работах [19; 20] и связан с такой важной частью электронной образовательной среды современного вуза, как система электронного портфолио (е-портфолио). На примере педагогического образования авторы констатируют такие возможности е-портфолио, как мотивация к достижениям и результатам обучения, фиксация и оценка результатов (обучения, тестирования, практики), построение индивидуальной образовательной траектории; использование портфолио как части вступительного (магистратура) [19] экзамена, государственной итоговой аттестации [20]. Рекомендованная структура портфолио при этом соответствует видам деятельности выпускника, зафиксированным в федеральных государственных образовательных стандартах, и может содержать такие разделы, как «Педагогическая деятельность», «Научно-исследовательская деятельность», «Проектная деятельность», «Культурно-просветительская деятельность» [20, с. 66].

Однако данный, безусловно полезный, опыт не может быть механически перенесен (обобщен) на другие направления подготовки. Для сравнения рассмотрим направление подготовки 09.03.03 Прикладная информатика (в ФГБОУ ВО «Самарский государственный социально-педагогический университет» подготовка студентов ведется по профилю «Прикладная информатика в государственном и муниципальном управлении»). Данное направление массовое (в 2018 году в России принято 12800 обучающихся, что составляет $1,7 \%$ от общего числа бакалавров) и в целом по структуре набор соответствует средним показателям (табл. 1) - нет выраженного преобладания целевиков, лиц с ограниченными возможностями здоровья или обучающихся по договорам об оказании платных услуг.

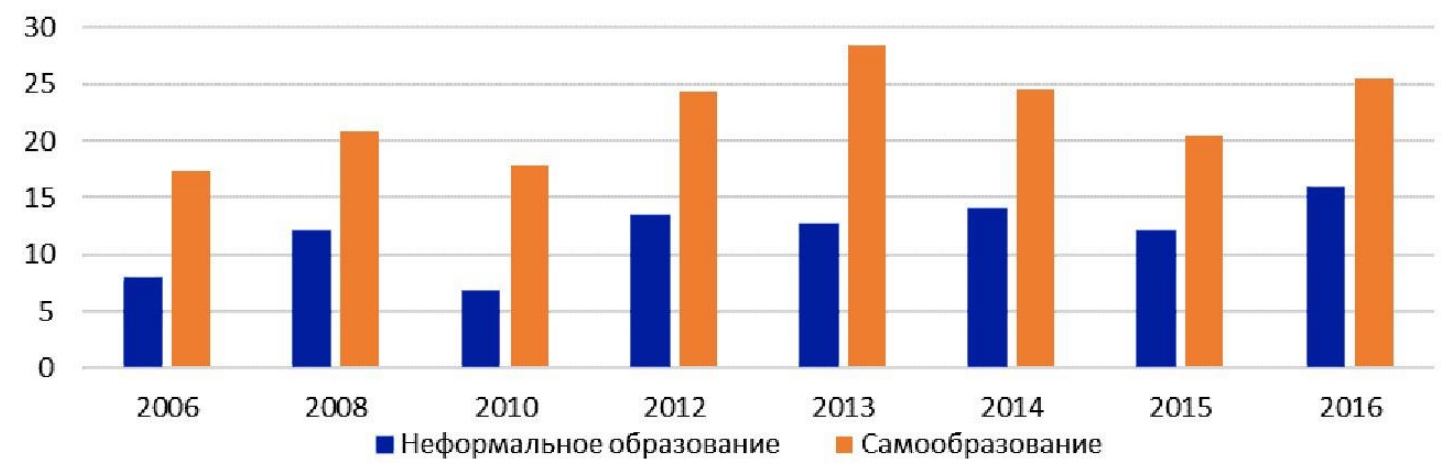

Рисунок 3 - Участие населения в различных формах непрерывного образования (диаграмма составлена по данным [5, с. 44-46]) 
Таблица 1 - Статистические показатели подготовки по направлению «Прикладная информатика» в 2018 году (составлено на основе данных Росстата)

Наименование направления подготовки (специальности) по перечням, утв. приказом Минобрнауки России от 12.09.2013 г. № 1061

\begin{tabular}{|c|c|c|c|c|c|c|}
\hline \multicolumn{4}{|c|}{ утв. приказом Минобрнауки России от 12.09.2013 г. № 106} & ата - всего & форматика & $\%$ \\
\hline \multicolumn{4}{|c|}{ Код направления подготовки (специальности) } & & 09.03 .03 & \\
\hline \multirow{4}{*}{$\begin{array}{l}\text { Подано } \\
\text { заявле- } \\
\text { ний на } \\
\text { обуче- } \\
\text { ние }\end{array}$} & \multicolumn{3}{|c|}{ за счет бюджетных ассигнований } & 2553979 & 60325 & $2,36 \%$ \\
\hline & \multirow[b]{2}{*}{ из них } & \multicolumn{2}{|c|}{ на места в рамках квоты целевого приема } & 28342 & 267 & $0,94 \%$ \\
\hline & & \multicolumn{2}{|c|}{$\begin{array}{l}\text { на места в пределах квоты приема лиц, } \\
\text { имеющих особое право }\end{array}$} & 42884 & 755 & $1,76 \%$ \\
\hline & \multicolumn{3}{|c|}{ по договорам об оказании платных образовательных услуг } & 1294786 & 18952 & $1,46 \%$ \\
\hline \multirow[b]{2}{*}{$\begin{array}{l}\text { Приня- } \\
\text { то }\end{array}$} & \multicolumn{3}{|l|}{ всего } & 741059 & 12800 & $1,73 \%$ \\
\hline & \multicolumn{3}{|c|}{$\begin{array}{l}\text { из них лица с ограниченными возможностями здоровья } \\
\text { (далее - ОВ3), инвалиды, дети-инвалиды }\end{array}$} & 5420 & 140 & $2,58 \%$ \\
\hline \multirow{7}{*}{$\begin{array}{l}\text { В том } \\
\text { числе } \\
\text { на обу- } \\
\text { чение }\end{array}$} & \multirow{6}{*}{$\begin{array}{l}\text { за счет бюджетных } \\
\text { ассигнований }\end{array}$} & \multirow{2}{*}{$\begin{array}{l}\text { федерально- } \\
\text { го бюджета }\end{array}$} & всего & 294885 & 6184 & $2,10 \%$ \\
\hline & & & $\begin{array}{l}\text { из них лица с ОВ3, } \\
\text { инвалиды, дети-инвалиды }\end{array}$ & 4683 & 128 & $2,73 \%$ \\
\hline & & \multicolumn{2}{|c|}{ бюджета субъекта Российской Федерации } & 11714 & 145 & $1,24 \%$ \\
\hline & & \multicolumn{2}{|c|}{ местного бюджета } & 149 & 11 & $7,38 \%$ \\
\hline & & & $\begin{array}{l}\text { на места в рамках квоты } \\
\text { целевого приема }\end{array}$ & 21843 & 240 & $1,10 \%$ \\
\hline & & & $\begin{array}{l}\text { на места в пределах } \\
\text { квоты приема лиц, } \\
\text { имеющих особое право }\end{array}$ & 13187 & 234 & $1,77 \%$ \\
\hline & \multicolumn{3}{|c|}{ інии платных образовательных услуг } & 434311 & 6460 & $1,49 \%$ \\
\hline
\end{tabular}

Интервью со студентами данного направления показали, что традиционное для педагогического вуза портфолио, по их мнению, не будет востребовано в их дальнейшей профессиональной деятельности. Эти выводы подтверждает и анализ вакансий, в которых потенциальный работодатель запрашивает от специалиста по сопровождению программного обеспечения не сертификаты об участии в «Студенческой весне», а профиль на github, приложения в Google Play, примеры созданных студентом сайтов или сертификаты, подтвержденные 1C.

\section{Выводы исследования}

и перспективы дальнейших изысканий

\section{данного направления}

По результатам проведенного исследования можно сформулировать ряд выводов.

1. Система высшего образования может и должна готовить выпускников к дальнейшему непрерывному образованию на протяжении всей жизни.

2. Одним из инструментов такой подготовки выступает электронное портфолио, обеспечивающее, в числе прочих, мотивацию, регистрацию студенческих достижений в учебе, внеучебной деятельности, возможность построения индивидуальной образовательной траектории (в том числе и внедрения онлайн-курсов в учебный процесс).

3. Чтобы портфолио стало востребованным не только администрацией вуза и контролирующими органами, необходимо, на наш взгляд, выполнение ряда условий:

- выработка единых отраслевых стандартов портфолио для каждого направления подготовки;

- переход от слабоструктурированной модели хранения (набор папок) к единой, унифицированной в рамках направления базе данных с развитой системой поиска информации (чтобы работодатель, мог, к примеру, найти всех студентов, имеющих в портфо- лио сайты на Wordpress), с учетом требований защиты персональных данных;

- размещение портфолио всех студентов России на одной или нескольких платформах, с возможностью свободной передачи данных в рамках вертикальной и горизонтальной академической мобильности;

- обеспечение возможности ссылок на внешние ресурсы (это может быть github для программистов и тест в ЯКлассе для педагогов, например с автоматизированным контролем их корректности);

- создание системы взаимооценки и экспертной оценки со стороны работодателей портфолио, что позволит указать студентам направления дальнейшего саморазвития.

\section{Список литературы:}

1. Статистическое измерение соответствия квалификации занятого населения выполняемой работе (данные Федеральной службы государственной статистики) [Электронный ресурс] // Федеральная служба государственной статистики - http://gks.ru/ free_doc/new_site/population/trud/stat-izm.pdf.

2. Райхерт Т.Н., Сыромятников В.Н. Динамическое обучение как основа методики преподавания дисциплин информационного цикла // Вестник Уральского института экономики, управления и права. 2016. № 3 (36). С. 74-79.

3. Система переподготовки преподавательских кадров и ее роль в повышении качества образования / А.Л. Бусыгина, В.А. Гусев, С.В. Левина, В.Н. Лисачкина и др. // Известия Самарского научного центра Российской академии наук. Социальные, гуманитарные, медико-биологические науки. 2017. Т. 19, № 6. С. 12-17.

4. Пархитько Н.П. Развитие непрерывного образования в России. Проблемы и перспективы // Постсоветские исследования. 2019. № 4. С. 1210-1216. 
5. Петров Ю.Н. Региональная система непрерывного многоуровневого профессионального образования: Аспект управления: дис. ... д-ра пед. наук. Нижний Новгород, 1996. 220 с.

6. Додока С.Н. Структура и технология формирования информационно-обучающего пространства в системе непрерывного образования: дис. ... д-ра пед. наук. М., 2003. 433 с.

7. Маливанов Н.Н. Теория и практика формирования в системе непрерывного образования: профессионально важных качеств инженера как субъекта инновационной деятельности: дис. ... д-ра пед. наук. Казань, 2005. 370 с.

8. Просвиркин В.Н. Технология преемственности в системе непрерывного образования: дис. ... д-ра пед. наук. М., 2008. 557 с.

9. Овчинникова И.Г. Развитие информационной культуры обучающихся в системе непрерывного образования: дис. ... д-ра пед. наук. Магнитогорск, 2009. $341 \mathrm{c}$

10. Орешкина А.К. Методологические основы преемственности образовательного процесса в системе непрерывного образования: дис. ... д-ра пед. наук. M., 2009. 417 c.

11. Пищулина Т.В. Становление студента вуза как объекта непрерывного профессионального образования: дис. ... д-ра пед. наук. Челябинск, 2012. $367 \mathrm{c}$.

12. Теплая Н.А. Многоуровневая система формирования информационной культуры обучающихся инженерного профиля в условиях непрерывного образования: дис. ... д-ра пед. наук. Шуя, 2016. 463 с.

13. Индикаторы образования: 2018: статистический сборник / Н.В. Бондаренко, Л.М. Гохберг, Н.В. Ковалева и др. М.: НИУ ВШЭ, 2018. 400 с.

\section{STUDENTS' SELF-DEVELOPMENT THROUGH THE PRISM OF ELECTRONIC PORTFOLIO}

(C) 2019

Dobudko Tatiana Valerianovna, doctor of pedagogical sciences, professor, head of Computer Science, Applied Mathematics and Teaching Methods Department Gorbatov Sergey Vasilievich, candidate of pedagogical sciences, associate professor of Computer Science, Applied Mathematics and Teaching Methods Department

Dobudko Alexandr Valerianovich, candidate of pedagogical sciences, associate professor of Computer Science, Applied Mathematics and Teaching Methods Department Pugach Olga Isaakovna, candidate of pedagogical sciences, associate professor of Computer Science, Applied Mathematics and Teaching Methods Department Samara State University of Social Sciences and Education (Samara, Russian Federation)

Abstract. The following paper discusses one of the urgent tasks of higher education at the present stage - the development of the personality of a specialist capable of self-development in the conditions of education digitalization in the Russian Federation. The creation of the system of continuous education in Russia is primarily the result of this process, as specialists' self-education is a necessary condition for successful employment, career growth, social and professional mobility at the present time. At the same time, the needs and opportunities of various forms of continuing education are unevenly distributed in various industries. So the IT industry requires constant self-education of employees. Practice shows that secondary general education, as a rule, does not develop the necessary skills of graduates' self-education. Therefore, the issues of management of bachelors' self-development as well as the formation of readiness for continuous education are very relevant for higher education. The paper describes conditions for the development of bachelors' readiness to continue education in its various forms (formal, informal) using the electronic portfolio system, which is an integral part of the electronic information and educational environment (EIEE) of the University. The obtained materials can serve as a basis for the development of a single electronic educational space of Russian universities.

Keywords: digitalization of education; electronic information and educational environment; electronic educational space; continuous education; self-education; self-development; electronic portfolio; culture of independent work of individual; academic mobility; employer; higher education. 